\title{
Patologia forense nas mortes com evidente ação do fogo
}

\author{
Forensic pathology in deaths caused by fire
}

\author{
Luiz Airton Saavedra de Paiva'
}

Paiva LSA de. Patologia forense nas mortes com evidente ação do fogo. Saúde, Ética \& Justiça. 2006;11(1/2):1-7.

RESUMO: Na autópsia de vítimas de ação do fogo nem sempre é fácil determinar a causa e a maneira da morte. 0 presente trabalho descreve os principais mecanismos fisiopatológicos resultantes da ação do fogo relacionados aos achados de autópsia, que possam contribuir com a determinação da causa e da maneira da morte.

DESCRITORES: Medicina legal. Autópsia. Patologia legal. Causa da morte. Vítimas de desastres.

\section{INTRODUÇÃO}

ntre os grandes desafios com que se deparam os patologistas forenses em autópsias de vítimas que apresentam sinais de que sofreram ação do fogo, está a constatação de que a vítima tinha vida, ao momento dessa ação. Este importante aspecto, no entendimento de Spitz ${ }^{1}$, é imprescindível à determinação da causa da morte e, conseqüentemente, da maneira da morte, se acidental, suicídio ou homicídio.

São sobejamente conhecidas as estratégias de que se valem alguns criminosos, interessados no acobertamento de seus atos que conduza à impunidade, quando, após cometerem um homicídio, procuram dissipar os vestígios reveladores do crime submetendo os cadáveres de suas vítimas a elevadas temperaturas, em pretensa simulação de acidente com ação do fogo.

Com esta finalidade, a extinção da vida em alguns homicídios é praticada através de formas, que pela escassez de vestígios encontrados, principalmente após a ação do fogo sobre o cadáver, a verdadeira maneira como a morte ocorreu permaneça dissimulada, confundindo-se com outras maneiras de morte traumática acidental pelo fogo. Daí a importância da afirmação de Simonin ${ }^{2}$ de que "a carbonização é um modo de dissimular um homicídio" (Figuras 1 e 2).

O objetivo deste trabalho, portanto, será o de rever os principais mecanismos fisiopatológicos decorrentes da ação do fogo relacionados com os achados da autópsia dessas vítimas.

${ }^{1}$ Médico Legista Classe Especial da SSP-SP, Mestre e Doutor em Ciências pela Faculdade de Medicina - USP. Endereço para correspondência: Av. Capitão Manoel Rudge, 707. Jardim Monte Libano - Mogi das Cruzes, SP. CEP 08780-290 


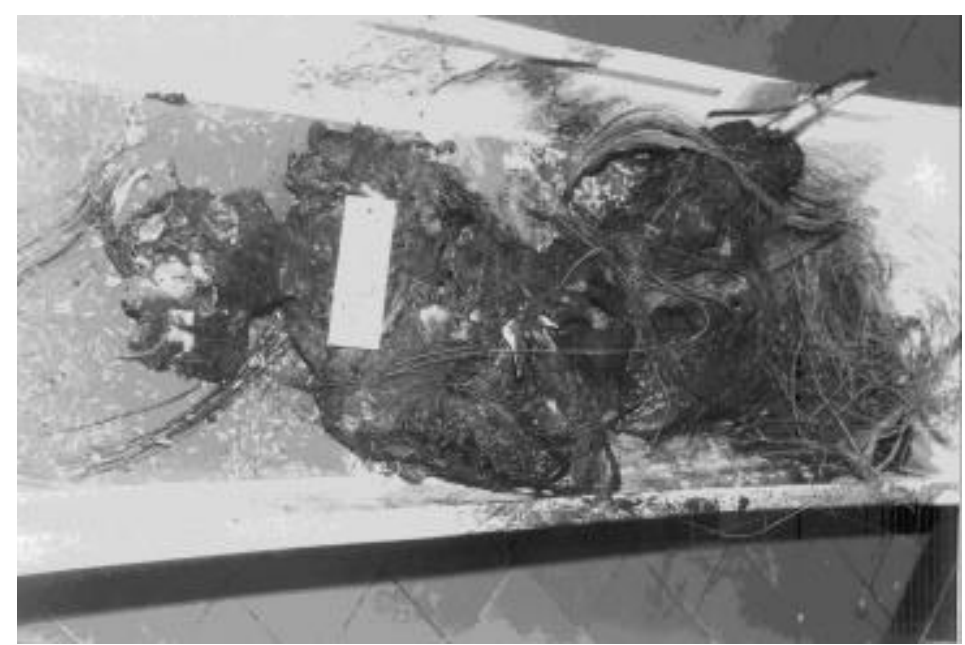

Figura 1 - Cadáver com evidente ação de fogo.

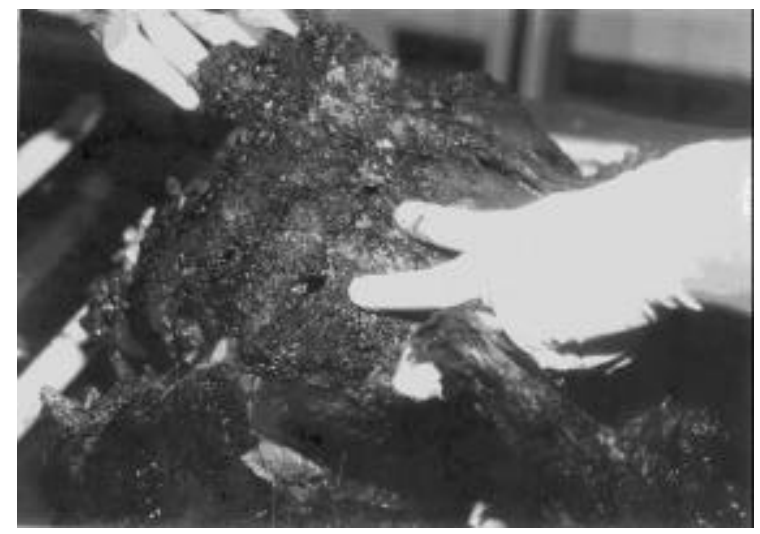

Figura 2 - Duplo ferimento de entrada de projétil de arma de fogo, em região dorsal do cadáver da figura anterior.

\section{Tipos de lesão pelo calor}

O calor pode produzir danos através de um mecanismo de ação geral, ou sistêmica (insolação e intermação), ou através de ação local, chamada queimadura.

DiMaio e DiMaio ${ }^{3}$ descrevem seis categorias de queimaduras:

1. Chamuscamento - quando existe verdadeiro contato da chama com o corpo produzindo lesão progressiva da pele até a carbonização;

2. Queimadura por contato - quando ocorre contato direto entre o corpo e a superfície de um objeto aquecido;
3. Queimadura por radiação de calor - quando não existindo contato entre o corpo e a chama, ou com superfície aquecida, a lesão é produzida através de onda de calor;

4. Escaldadura - quando ocorre contato com líquidos aquecidos, mais comumente com água;

5. Queimadura química - produzida pelo contato com agentes químicos;

6. Queimadura por microonda - produzida por radiação eletromagnética de elevadíssima freqüência, de onda de comprimento muito curto.

Para atender os objetivos deste trabalho, limitaremos o estudo apenas às lesões produzidas pela ação do fogo, ficando excluídas as lesões por contato com superfícies aquecidas, por agentes químicos e por microonda. 


\section{Lesões por ação do fogo}

Com relação às lesões pelo calor, Spitz ${ }^{1}$ tece algumas considerações. Afirma que a severidade da lesão depende diretamente da intensidade do calor e da duração do tempo de exposição, e que as temperaturas do fogo diferem consideravelmente na dependência do material queimado. Alguns incêndios provenientes da combustão de certas substâncias químicas atingem rapidamente alguns milhares de graus de temperatura, enquanto incêndios domésticos raramente excedem 600 a $700{ }^{\circ} \mathrm{C}$. Considera incomum que um corpo de adulto queime completamente em incêndios, sem deixar vestígios, ao contrário de crianças até os primeiros anos de vida. Afirma que a obesidade e as vestes contribuem para apressar e tornar mais completa a destruição de um corpo pelo fogo. Entretanto, quando artigos são utilizados de forma mais justa ao corpo, como cintos, meias e sapatos, preservam a pele subjacente devido à exclusão do ar. Em incêndios domésticos devastadores um corpo pode ser gravemente carbonizado em menos de 20 minutos, e cita Richards ${ }^{4}$ ao considerar que se faz necessário um considerável tempo para que um corpo queime a cerca de $700{ }^{\circ} \mathrm{C}$ até que os ossos sejam expostos. Nessa condição, o gradeado costal, o esqueleto facial e os ossos dos braços são expostos em cerca de 20 minutos, enquanto as pernas se apresentarão severamente carbonizadas, porém seus ossos somente estarão expostos após 25 minutos e a queima completa das partes moles das coxas e dos ossos da canela não ocorrerão antes dos 35 minutos. A utilização de líquido inflamável, como querosene ou gasolina, sobre o corpo com o objetivo de acelerar sua destruição pode apresentar irregularidade na carbonização, com severidade desproporcional entre os segmentos corporais. Afirma também que se o tecido adiposo entrar em combustão, uma prolongada e lenta queima pode causar severo dano ao esqueleto, incluindo amputação (calcinação). Chama a atenção para os traços de fratura caracteristicamente encurvados observadas em ossos carbonizados que ocorrem durante o processo de seu resfriamento.

As mortes pelo fogo podem, segundo DiMaio e DiMaio ${ }^{3}$, serem imediatas ou tardias. As mortes tardias que ocorrem dentro dos primeiros três dias são causadas por choque, perdas líquidas, ou falência respiratória aguda causada por inalação de gases que produzem lesão na árvore respiratória.

A morte imediata, ou morte no local, pode ocorrer tanto por lesão térmica direta sobre o corpo, denominando-se queimadura, como pelo fenômeno da inalação de fumaça, o que ocorre mais freqüentemente.

A maioria dos autores considera que a lesão por inalação de fumaça, ou de gases aquecidos, represente a principal causa de mortalidade entre as vítimas do fogo. Spitz ${ }^{1}$ afirma que em três quartos de todos os casos, a morte pelo fogo resulta da inalação de fumaça tóxica, enquanto Demling ${ }^{5}$ considera que o mesmo ocorra em mais de $50 \%$ dos casos, sendo esse problema a maior fonte de morbidade desses pacientes.

Gerling et al. ${ }^{6}$ relacionaram como processos patológicos que produzem a morte no local, nas vítimas da ação do fogo, e/ou do calor:

1. o envenenamento por cianeto liberado a partir da queima de certos materiais sintéticos (nylon, seda, lã, poliuretano,...);

2. a parada respiratória, seguindo a respiração no fogo, através de laringobroncoespasmo, ou de reflexo vagal, ou ainda por choque causado pela inalação de calor (gases aquecidos);

3. a deficiência de oxigênio devido ao elevado consumo do componente atmosférico pelo fenômeno da combustão;

4. o choque causado pela redistribuição do volume dos líquidos do sangue produzido pela lesão direta da pele;

5. a rigidez torácica produzida pela lesão térmica direta sobre o tronco;

6. outra causas naturais e não naturais.

\section{Exame do cadáver queimado}

A severidade da lesão pelo calor, depende:

- da extensão da área comprometida;

- da profundidade e localização das lesões;

- da idade da vítima;

- da presença de lesões por inalação de fumaça.

A extensão é avaliada através da aplicação da "Regra dos Nove" de Pulaski e Tennisson, segundo França ${ }^{7}$, mostrada de forma modificada abaixo (Figura 3). Simonin ${ }^{2}$ afirma que uma queimadura que cubra $50 \%$ da superfície corporal é mortal de 06 a 12 horas. Entretanto considera que queimaduras graves, que atingem 40 a $60 \%$ da superfície podem curar com os modernos tratamentos especializados. 


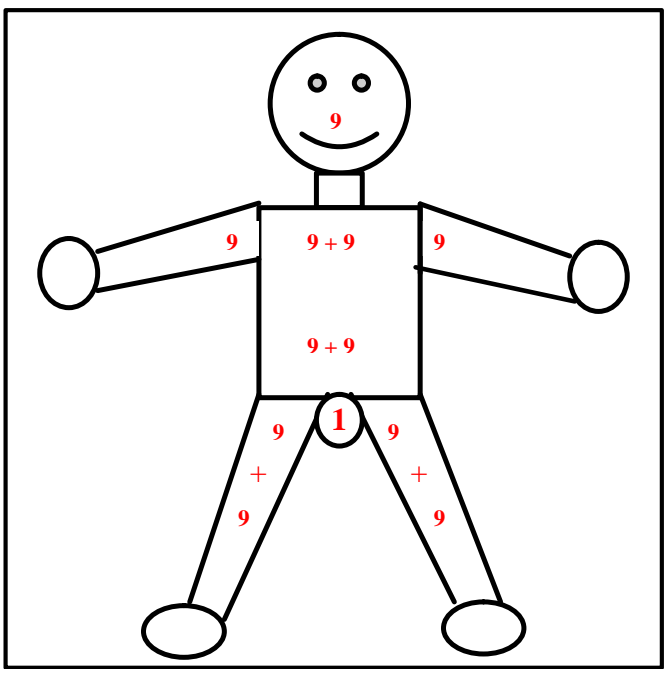

Figura 3 - Regra dos nove.
O comprometimento em profundidade é mostrado de forma esquemática abaixo (Figura 4). Essa profundidade atingida pelas lesões é avaliada preferencialmente pela Classificação de Hoffmann, em quatro graus, conforme apresentada por França ${ }^{7}$ e descrita por DiMaio e DiMaio:

$1^{\circ} \mathrm{Grau}$ - interessa apenas a epiderme e apresenta como aspecto o eritema;

$2^{\circ}$ Grau - acomete parcialmente a derme e apresenta como aspecto vesículas ou flictenas;

3 Grau - ocorre a necrose coagulativa da epiderme e derme, comprometendo a pele em profundidade sem atingir plano anatômico abaixo dela.

Produz o aspecto da escara, podendo apresentar-se a lesão em cor cinza ou negra devido ao grau de carbonização;

4ํㅡrau - mais destrutiva, acomete planos anatômicos abaixo da pele.

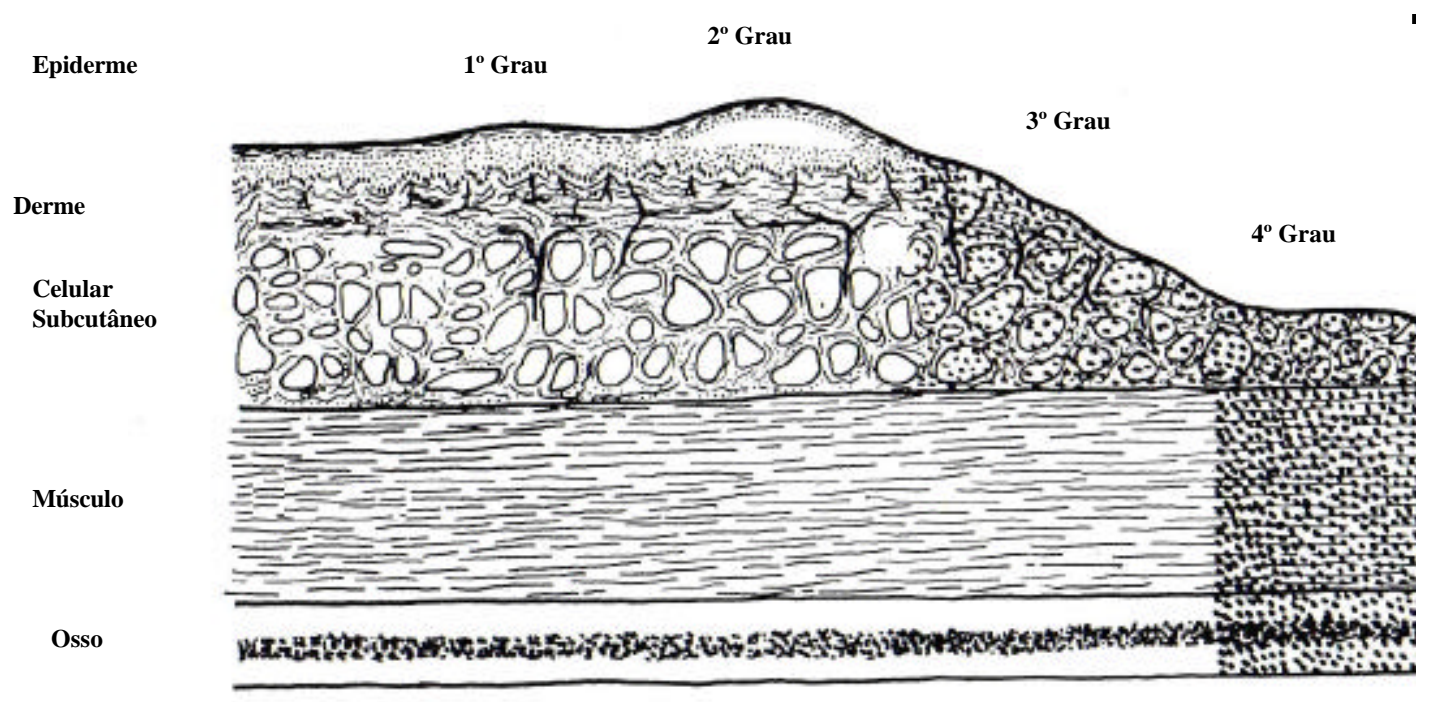

Figura 4 - Classificação relativa à profundidade atingida pela lesão (modificado de Simonin²).

Corpos que sofrem extensa carbonização apresentam-se na atitude de boxeador, devido à contração muscular produzida pelo calor. A pele pode apresentar rupturas. Quando a pele é completamente destruída, a exposição das camadas musculares pode mostrar essas rupturas, devido também ao efeito do calor.

Considerados esses dois parâmetros, extensão e profundidade, Teixeira ${ }^{8}$ afirma, com base em sua experiência, que nas queimaduras do $2^{\circ}$ grau com mais de $30 \%$ de área corporal comprometida, a lesão é grave (perigo de vida), e acima de $70 \%$ são seguidas freqüentemente de óbito. As do $3^{\circ}$ grau com mais de $10 \%$ de área corporal comprometida também são graves.

Restos de vestes, assim como fragmentos de pele queimada ressecada (com aspecto de couro), podem ser utilizados em análise para detecção de possíveis agentes químicos utilizados como acelerantes para o fogo (Spitz $\left.{ }^{1}\right)$. 
O peso e a altura de um cadáver carbonizado provavelmente estarão alterados devido ao dessecamento dos tecidos, às fraturas do esqueleto e à pulverização dos discos intervertebrais pelo calor, segundo Spitz ${ }^{1}$.

Em carbonizados é comum a completa destruição dos tecidos moles da face e da calvária, onde se pode observar na tábua óssea externa (ectocrânio) uma fina rede de fraturas pelo calor, podendo mesmo esta camada externa sofrer fragmentação e estar ausente ${ }^{3}$.

No exame da cabeça, importante considerar existência de um artefato muito freqüente, a presença de hematoma extradural de origem postmortem, que segundo DiMaio e DiMaio ${ }^{3}$, não são difíceis em serem distinguidos do hematoma de origem antemortem, já que apresentam coloração marrom achocolatada, tendo aspecto friável em favo-de-mel. São extensos, espessos, e comumente ocupam a áreas frontais, temporais, em alguns casos estendendo-se à área occipital.

Cataratas são um achado postmortem, ocorrendo com temperaturas baixas, cerca de $60^{\circ} \mathrm{C}$ a $70^{\circ} \mathrm{C}$, devido à coagulação das proteínas do cristalino ${ }^{1}$.

A língua pode se apresentar protuída devido à retração da pele da face, resultante da desidratação produzida pelo fogo ${ }^{1}$.

Os dentes, assim como os materiais empregados em dentística reparatória, por serem muito resistentes ao calor são importantes elementos a serem considerados para fins de identificação'.

Gases tóxicos presentes na fumaça, assim como partículas de carvão recobertas por aldeídos irritantes e ácidos orgânicos podem produzir lesão direta sobre as vias aéreas superiores, assim como em seus segmentos mais inferiores. Depressão respiratória e laringoespasmo, resultante de irritação das vias aéreas, funcionam como mecanismo protetor contra a exposição excessiva a essas substâncias, em vítimas conscientes. No paciente inconsciente, ocorre perda dessa proteção com resultante lesão mais severa das vias aéreas inferiores. Gases hidrossolúveis presentes na fumaça resultante da queima de plásticos, ou de borracha, como amônia, dióxido de enxofre e sais de cloro, reagem com a água presente na mucosa respiratória produzindo ácidos fortes e álcalis que provocam irritação, broncoespasmo, edema e ulceração da membrana. Ocorre importante agressão ao movimento ciliar da mucosa respiratória com conseqüente prejuízo da remoção de partículas depositadas e do muco ${ }^{5}$.

No tronco, independentemente da severidade da destruição da superfície corporal, os órgãos encontram-se bem preservados permitindo serem avaliados na autópsia. Mesmo com a completa destruição das paredes torácica e abdominal é freqüente o encontro de órgãos relativamente bem preservados.

Tecidos e fluidos corporais são usualmente utilizados para análises toxicológicas ${ }^{1}$.

\section{Determinação da causa da morte}

A determinação, na perícia, de que a morte ocorreu por ação do fogo nem sempre é tarefa fácil. DiMaio e DiMaio ${ }^{3}$ chegam a afirmar que, através do exame macroscópico, é usualmente impossível distinguir formas agudas de queimaduras produzidas em vida daquelas produzidas post mortem. Mesmo o exame microscópico da área da lesão não se apresenta proveitoso, a não ser que a vítima tenha sobrevivido tempo suficiente para desenvolver uma resposta inflamatória.

Entre as principais evidências, relatadas pela grande maioria dos autores, está a presença de fuligem em vias aéreas (Figura 5) e vias digestivas (indicadores de inalação e deglutição de fumaça respectivamente), e pela presença de carboxiemoglobina (resultante da combinação do monóxido de carbono com a hemoglobina) ou de cianeto no sangue.

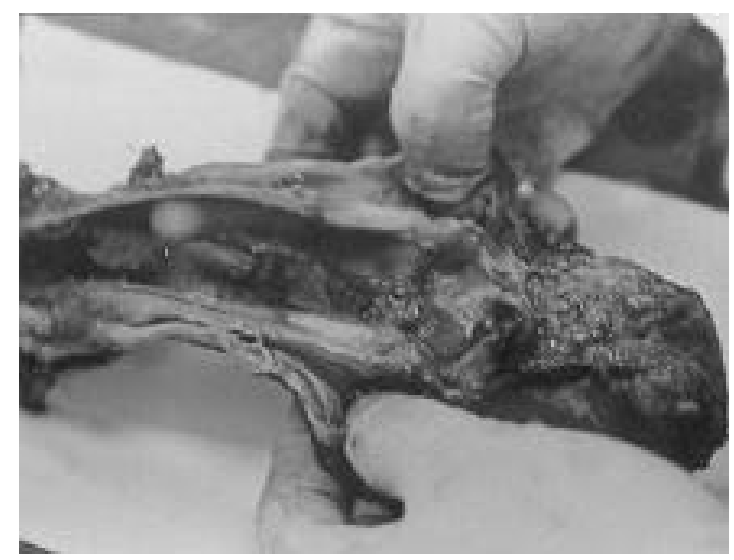

Figura 5 - Presença moderada de fuligem em traquéia.

Entretanto esses achados, que em última análise representariam a existência de fenômenos vitais durante a ação do fogo, não se apresentam com a desejável regularidade.

Para ressaltar este aspecto, Spitz ${ }^{1}$, tece considerações acerca das variações individuais na elevação dos níveis de carboxiemoglobina, quando 
Paiva LSA de. Patologia forense nas mortes com evidente ação do fogo.

considerada a idade da vítima, seu estado de saúde, e o hábito de fumar. Jovens e crianças podem produzir elevações de carboxiemoglobina a níveis fatais mais rápido que adultos expostos a uma mesma atmosfera, devido às elevadas taxas de metabolismo características dessa faixa etária. $\mathrm{Na}$ presença de enfisema pulmonar, doença aterosclerótica coronariana ou anemia, a morte pode ocorrer antes do monóxido de carbono atingir níveis elevados no sangue. Fumantes crônicos podem apresentar durante o dia saturação de $\mathrm{CO}$ (monóxido de carbono) de $8 \%$ a $10 \%$, o que obriga uma cuidadosa interpretação desses níveis, já que em não fumantes eles podem ser considerados evidência de inalação de fumaça.

Knight ${ }^{9}$ comentando a importância da morte ter ocorrido antes da ação do fogo, relaciona o achado de elevada concentração de carboxiemoglobina no sangue, assim como a presença de partículas de fuligem na boca, narinas e, principalmente, em laringe, traquéia e brônquios, como indicativos de que a vítima respirava após o início do fogo. Entretanto, enfatiza que o contrário não é verdadeiro, ou seja, a ausência de fuligem e de elevada concentração de carboxiemoglobina pode ocorrer em casos de formação rápida de labaredas, como em explosão por gasolina em veículos, onde pouca fuligem e monóxido são produzidos.

Gerling et al. ${ }^{6}$, confirmando o que foi afirmado acima, em um estudo retrospectivo sobre 115 vítimas da ação do fogo autopsiadas, em que 85 morreram no local, desse último contingente de casos, a inalação de fuligem foi positiva em $80 \%$, a deglutição de fuligem foi constatada em $30,6 \%$ e a carboxiemoglobina considerada elevada (acima de $10 \%$ ) em $75,3 \%$. Os três achados só apareceram juntos em $28,2 \%$ desses casos.

Spitz ${ }^{1}$ afirma que, contrariamente ao acreditado, flictenas na pele, características de queimaduras do $2^{\circ}$ grau, não necessariamente indicam reação vital, podendo se formar até pouco tempo depois da morte e não se distinguem das fases precoces da putrefação. Afirma também que o fino halo avermelhado observado ao redor de áreas de pele queimada resulta de sangue e fluidos teciduais acumulados, e não é indicativa de resposta inflamatória. Queimaduras produzidas experimentalmente em cadáver, principalmente em área de lividez visível, confirmam o aparecimento desta área circundante avermelhada. Em sentido inverso, DiMaio e DiMaio ${ }^{3}$, também comentando a dificuldade de estabelecer se a morte ocorreu antes ou depois da ação do fogo, mesmo com a utilização do exame microscópico, relatam que exame histológico em queimaduras do $3^{\circ}$ grau, de pacientes que faleceram com dois ou três dias de evolução, não apresentava reação inflamatória, presumivelmente devido à trombose dos vasos da derme, que impede às células inflamatórias alcançar a área de queimadura e produzir a reação.

\section{Identificação do cadáver carbonizado}

Na grande maioria das vítimas de ação do fogo, a morte se dá por causa da inalação de fumaça, ocorrendo as lesões sobre o corpo de forma a produzir pouca, ou nenhuma alteração, permitindo sua identificação através dos meios usuais (reconhecimento e datiloscopia).

No cadáver carbonizado, é freqüente um elevado grau de destruição das estruturas faciais impedindo o reconhecimento fisionômico, assim como fica impossibilitada a coleta de impressões digitais pela destruição da pele dos dedos. Nestes casos, existindo sinais individuais característicos como cicatrizes, tatuagens, deformidades, ou ausência de órgãos, ás vezes é possível se fazer a identificação através dessas características.

Em geral, devido a grande resistência ao calor, tanto dos elementos dentários como dos materiais utilizados em dentística reparatória, o exame da arcada dentária, com a possibilidade de obtenção de registros antemortem da vítima, representa um meio prático, rápido, seguro e econômico de identificação. A realização de radiografia dentária, para comparação com registro radiográfico anterior da vítima, permite comparar a estrutura trabecular óssea, a forma e a apresentação dos dentes, assim como o desenho da conformação radicular. DiMaio e DiMaio $^{3}$ comentam a vantagem desse procedimento por evitar o contato de parentes próximos com as vítimas desfiguradas.

Radiografias de outros segmentos, principalmente da cabeça, permitem também comparação do detalhamento anatômico, como dos seios da face, assim como o prévio registro de calcificações e concreções radiologicamente evidentes servem a esse objetivo.

Por último, técnicas de emprego de DNA, que pelo seu elevado custo e demora na sua realização, devem ser deixadas apenas para quando as demais técnicas aqui apresentadas não puderem de todo ser utilizadas.

\section{CONCLUSÃO}

Nas autópsias de vítimas com evidente ação do fogo, ao lado do rotineiro rigor técnico que exige a prática pericial forense, atenção especial deve ser 
dada à determinação da causa e da maneira da morte. Objetivo nem sempre fácil de atingir, dado às extensas modificações produzidas nos corpos nesta circunstância, podendo levar à confusão em sua interpretação, como rupturas da pele, fraturas da calota craniana, hematoma extradural, e outras aqui descritas. Uma avaliação da extensão de área corporal comprometida e da profundidade e localização das lesões, assim como da presença ou não de reação vital deve ser realizada, com o intuito inicial de determinar se havia vida no momento da ação do fogo, e se o comprometimento causado por essa ação, por si, seria capaz de produzir a morte. Cuidadosa análise das alterações observadas em todos os segmentos corporais, tanto ao exame externo como interno, assim como exames radiográficos e coleta de materiais biológicos para exames histopatológicos e toxicológicos, poderão contribuir para conclusões cientificamente mais sólidas dos objetivos da autópsia.

Paiva LSA de. Forensic pathology in deaths caused by fire. Saúde, Ética \& Justiça. 2006;11(1/2):1-7.

ABSTRACT: It's difficult to determine the cause and manner of death in forensic autopsy of victims with severely burned bodies. This work describes the main physiological derangements in the body that result in the death of the individual.

KEY WORDS: Forensic medicine. Autopsy. Forensic pathology. Cause of death. Disaster victims.

\section{REFERÊNCIAS}

1. Spitz WU, Fisher RS. Spitz and Fisher's medicolegal investigation of death. 3a. ed. Springfield, IL: Charles C. Thomas; 1993.

2. Simonin C. Medicina legal judicial. 2a. ed. Barcelona: ED. JIMS; 1973.

3. DiMaio DJ, DiMaio VJM. Forensic Pathology. 2a. ed. Boca Raton, FL: CRC Press; 2001.

4. Richards NF. Fire investigation-destruction of corpses. Med Sci Law. 1977;17:79.

5. Demling, RH. Pulmonary problems in the burn patient (a leading cause of morbidity and mortality in the burn patient). J Burns Surg Wound Care (serial online) 2004;3:5. Available from: http://www.journalofburns.com

6. Gerling I, Meissner C, Reiter A, Oehmichen M. Death from thermal effects and burns. Forensic Sci Int. 2001;115:33-41.

7. França GV. Medicina legal. 7a. ed. Rio de Janeiro: Guanabara-Koogan; 2004.

8. Teixeira WRG. Manual de medicina legal. Mogi das Cruzes, SP: Graph Center Express; 2000.

9. Knigth B. Simpson's forensic medicine. 11th. ed. London: Arnold; 1997. 